\title{
COMPARISON OF RADIAL SHOCKWAVES AND CONVENTIONAL PHYSIOTHERAPY FOR TREATING PLANTAR FASCIITIS
}

\author{
Júlia Maria D’Andréa Greve, Marcus Vinicius Grecco, Paulo Roberto Santos- \\ Silva
}

doi: $10.1590 / \mathbf{S 1 8 0 7 - 5 9 3 2 2 0 0 9 0 0 0 2 0 0 0 0 6}$

D’Andréa Greve JM, Grecco MV, Santos-Silva PR. Comparison of radial shockwaves and conventional physiotherapy for treating plantar fasciitis. Clinics. 2009;64:97-103.

OBJECTIVE: To compare radial shockwave treatment and conventional physiotherapy for plantar fasciitis.

MATERIALS AND METHODS: Thirty-two patients with plantar fasciitis were included in this study. They were randomly divided into two groups. Group 1 was composed of 16 patients who underwent 10 physiotherapy sessions each, consisting of ultrasound, kinesiotherapy and instruction for stretching exercises at home. Group 2 was composed of 16 patients who underwent three applications of radial shockwaves (once a week) and received instruction for stretching exercises at home. Pain and ability to function were evaluated before treatment, immediately afterwards, and three months later. The mean age of the patients was $47.3 \pm 10.3$ years (range 25-68); $81 \%$ were female, $87 \%$ were overweight, 56\% had bilateral impairment, and $75 \%$ used analgesics regularly. RESULTS: Both treatments were effective for pain reduction and for improving the functional abilities of patients with plantar fasciitis. The effect of the shockwaves was apparent sooner than physiotherapy after the onset of treatment.

CONCLUSION: Shockwave treatment was no more effective than conventional physiotherapy treatment when evaluated three months after the end of treatment.

KEYWORDS: Plantar fasciitis; Sockwave therapy; Physiotherapy.

\section{INTRODUCTION}

Shockwaves have been used for 15 years as an alternative treatment for musculoskeletal disorders. ${ }^{1,2}$ The treatment consists of mechanical acoustic waves that are transmitted through liquid and gaseous media. ${ }^{1-3}$ Their biological effect comes from the mechanical action of (mechanical) ultrasonic vibrations on tissues. ${ }^{2-4}$

Shockwaves can be focal or radial. Focal shockwaves have high tissue penetration power $(10 \mathrm{~cm})$ and impact force $\left(0.08-0.28 \mathrm{mj} / \mathrm{mm}^{2}\right)$. They produce mechanical and biological effects of greater intensity, including destruction

Laboratório de Estudos do Movimento - LIM 41 - Departamento de Ortopedia e Traumatologia da Faculdade de Medicina da Universidade de São Paulo, São Paulo/SP, Brazil

Email: jgreve@usp.br

Tel.: 5511 3069-6041

Received for publication on September 17, 2008

Accepted for publication on October 21, 2008 of fibrosis and stimulation of neovascularization in treated tissues. ${ }^{1-3}$ Radial shockwaves are pneumatic waves that are generated by air compressors. They transmit radially, with lower penetration $(3 \mathrm{~cm})$, less impact $\left(0.02-0.06 \mathrm{mj} / \mathrm{mm}^{2}\right)$ and limited biological effect. ${ }^{5}$ They have been shown to be effective for treating musculoskeletal disorders that are more superficial, with clinical results that are similar to those of focal shockwaves. ${ }^{2,6,7}$ The effect of radial shockwaves is less intense, but they have been shown to cause disintegration of fibroses and calcifications and increase blood circulation at the treated location. ${ }^{5-9}$

Plantar fasciitis is a degenerative abnormality of the plantar fascia that affects up to $10 \%$ of the general population. ${ }^{10,11}$ Shortening caused by changes in the collagen matrix of the plantar fascia is the pathophysiological basis of this disease, which evolves to include pain and functional changes of gait. ${ }^{1,3,12-14}$ Shortening of the plantar fascia leads to chronic bone traction in the heel and formation of heel spurs. The preferred treatment is physiotherapy, with 
the aim of suppressing pain and restoring the mechanical function of the plantar fascia for gait improvement. The use of ultrasound to promote analgesia associated with stretching of the plantar fascia and the posterior leg muscles is one of the most commonly indicated therapeutic alternatives. ${ }^{10,11,14,15}$ Treatment of plantar fasciitis using focal and radial shockwaves has shown good results with regard to pain reduction and improved function using only a small number of applications (three to six)., 1,3,-7,14

The aim of the present study was to compare the results of two conservative plantar fasciitis treatments:

- Treatment 1 - application of ultrasound and kinesiotherapy: stretching of the posterior muscle chain of the legs (ischiotibial and sural triceps) and strengthening of the tibialis anterior performed by a physiotherapist, together with instruction for active stretching of the gastrocnemius and plantar fascia to be performed at home.

- Treatment 2 - application of radial shockwaves, together with instruction for active stretching of the gastrocnemius and plantar fascia to be performed at home.

\section{METHOD}

This was a randomized, prospective and comparative clinical study.

\section{Sample}

Thirty-two patients with plantar fasciitis that was diagnosed by anamnesis, physical examination and ultrasonography were treated. All patients agreed to participate in the study and signed a free and informed consent statement. The inclusion criteria were:

- diagnosis of plantar fasciitis, with plantar fascia of more than $4 \mathrm{~mm}$ thickness as evaluated by ultrasonography;

- age between 20 and 68 years;

- literate;

- painful symptoms lasting three months or more;

- absence of heart pacemaker use;

- absence of anticoagulant use and absence of coagulation disease;

- absence of other musculoskeletal disorders of any etiology with clinical manifestations in the lower limbs or vertebral column;

- absence of central or peripheral neuropathy of any etiology;

- absence of systemic inflammatory disease;

- absence of associated metabolic and endocrine diseases;

- absence of psychiatric disorders;

- ability to visit the hospital for treatment and evaluations.
The mean age of the patients was $47.3 \pm 10.3$ years (range 25-68 years). Twenty-six patients (81\%) were female and six (19\%) were male. Eighteen patients $(56 \%)$ were affected bilaterally, 24 (75\%) were using analgesics and 23 (72\%) had not undergone any previous treatment. Twentyeight patients (87\%) were considered to be overweight and only $11(34 \%)$ performed any regular physical activity.

\section{Treatment}

After the patients had been selected, they were divided into two groups of 16 participants each in accordance with randomly drawn numbers:

- Group 1 - Conventional physiotherapy: These patients were treated with ultrasound at a frequency of $1.0 \mathrm{~Hz}$ and intensity of 1.2 watts $/ \mathrm{cm}^{2}$. Ten sessions were undertaken at a frequency of two sessions per week. All patients performed exercises after ultrasound application to stretch all posterior leg muscles and strengthen the tibialis anterior. All patients were followed up and guided by the same physiotherapist in all sessions. All patients were advised to perform active stretching of the gastrocnemius and plantar fascia at home.

- Group 2 - Radial shockwave therapy: These patients were treated with applications of radial shockwaves, which were always administered by the same physician. Swiss Dolor Clast equipment was used with a low-intensity applicator. Two thousand beats were applied at a frequency of $6 \mathrm{~Hz}$ and a pressure of $3 \mathrm{MPa}$. The patients were positioned in ventral decubitus, with the dorsum of the foot supported on the edge of the bed. The applicator was placed perpendicular to the insertion of the plantar fascia into the calcaneus, and a gel was used to maintain contact with the skin. The sessions were performed once per week for a total of three sessions. All patients were advised to perform active stretching of the gastrocnemius and plantar fascia at home.

\section{Evaluation}

Evaluations were made before the treatment, immediately afterwards, and three months after treatment. These evaluations were always performed by the same examiner. The evaluations consisted of:

- Pain assessment

- Periodicity of pain, i.e. the number of times per week that patients experienced pain

- Duration of pain, i.e. the number of hours per day with pain

- Visual analog scale (VAS) assessment of morning pain, gait pain and orthostatic pain 
- Use of Fischer's algometer to quantify painful pressure on the insertion of the plantar fascia into the calcaneus and on the middle third of the medial gastrocnemius

- Use of analgesics during treatment.

\section{RESULTS}

There were no differences between groups 1 and 2 with regard to gender, age, physical activity, ethnicity, side affected or body mass index (BMI). Both groups showed improvement of pain symptoms including reduced number of episodes of pain per week (Table 1) and hours of pain per day (Table 2). There were decreases in the intensity of morning pain (Table 3), general pain (Table 4) and pain in the orthostatic position (Table 5), as evaluated using the VAS. There was a decrease in the intensity of pain in the calcaneus (Table 6) and calf (Table 6) when measured using Fischer's algometer. Most patients had decreased their intake of analgesics by the final evaluation at three months after treatment (Table 7). There was no statistically significant difference between the groups in any of the parameters used for evaluation.

\section{DISCUSSION}

The plantar fascia is one of the most important static structures that support the medial longitudinal arch. Plantar fasciitis occurs as a result of repetitive microtrauma at the origin of the medial tuberosity of the calcaneus; traction forces during support lead to an inflammatory process that results in fibrosis and degeneration. ${ }^{11}$ Heel spurs and nerve trapping (medial calcaneal, lateral plantar or fifth-finger abductor) can be associated with the inflammatory process. ${ }^{10}$ Women are affected more often than men. Plantar fasciitis is associated with obesity and the climacterium. ${ }^{14}$ In the present study, patients were more frequently female (81\%), mostly overweight (87\%), and their mean age was $47.3 \pm$ 10.3 years.

The occurrence of plantar fasciitis is related to professional and leisure activities that require support of body weight and is not related to loss of strength, muscle trophism or joint range of motion (ROM) ${ }^{16}$ Most patients in the present study (63\%) performed their work while standing (nurses, cleaners and security guards), thus indicating the importance of mechanical factors in the etiopathogenesis of this disease. None of the patients in this study presented loss of strength or decreased ROM. On the other hand, morning pain was reported by $85 \%$ of the patients, gait pain by $72 \%$ and orthostatic pain by $78 \%$; these findings are similar to those in other reports. Morning pain is an important evaluation criterion. In the present study, all patients quantified their morning pain as greater than or equal to five on the VAS before treatment. ${ }^{6,7,17}$ After treatment, 14 of the 16 patients in each group had VAS scores of less than five, thus suggesting that both treatments were effective for pain reduction.

Plantar fasciitis leads to lateral body weight support on the foot or forefoot (supported on the toes) during gait because of pain in the medial region of the calcaneus or at the proximal insertion of the plantar fascia; this leads to chronic shortening of the Achilles tendon and pain in the medial portion of the gastrocnemius. ${ }^{11,14,15}$ Fischer's algometer permits simple and reproducible quantification of pain in the medial tuberosity of the calcaneus and the medial portion of the gastrocnemius. In total, $22 \%$ of the patients reported intense pain in the calcaneus (up to $4 \mathrm{~kg}$ on Fischer's algometer), while $45 \%$ of the patients did not report any significant pain in the gastrocnemius at the first evaluation. This latter finding is in contrast to previous reports that pain was present in the calcaneus and gastrocnemius of most patients. The combination of fascitis with overweight may enhance the effects of the latter in altering postural balance. ${ }^{18}$

In many cases, planter fasciitis is bilateral. ${ }^{12}$ In the present sample, $56 \%$ of cases were bilateral. Chronic plantar fasciitis (symptoms lasting for more than three months) responds better to shockwave treatment than does the acute form (less than three months of symptoms) ${ }^{8,9}$ The present sample population only included chronic cases of plantar fasciitis.

Thickening of the plantar fascia to more than $4 \mathrm{~mm}$ has been correlated with greater intensity of pain and functional limitation, ${ }^{19-21}$ but this relationship was not observed in the present study. The thickness of the plantar fascia in the present study ranged from $4 \mathrm{~mm}$ to $9 \mathrm{~mm}$, but without any correlation with the intensity of the pain. Furthermore, no decrease in the ROM of the first metatarsal-phalangeal joint was observed, in contrast to the findings reported in the literature. ${ }^{16,22}$ Furthermore, there were no observed decreases in ankle- flexion or extension.

Surgical treatment of plantar fasciitis is rare. It does not always produce good results and recurrence occurs in $30 \%$ of cases. ${ }^{23-26}$ The first-choice treatment is conservative non-surgical treatment. ${ }^{27,28}$ Application of therapeutic ultrasound accompanied by stretching exercises is one of the most indicated physiotherapeutic treatments for plantar fasciitis. ${ }^{10,15}$ In the present study, the continuous form was used with constant wave intensity. The applied doses ranged from 1.2 to $3.0 \mathrm{~W} / \mathrm{cm}^{2} .{ }^{10}$ Radial shockwave therapy has shown good results without side effects, but it is a relatively new technology with high cost and needs to be comparatively evaluated with other types of conservative treatment. ${ }^{5-7}$ In the 
Table 1 - Weekly periodicity of pain symptoms in group 1 (conventional physiotherapy) and group 2 (shockwave physiotherapy) before treatment, immediately afterwards, and three months later

\begin{tabular}{|c|c|c|c|c|c|c|}
\hline \multirow[t]{2}{*}{ Weekly frequency of pain } & \multicolumn{3}{|c|}{ Group $1(n=16)$} & \multicolumn{3}{|c|}{ Group $2(n=16)$} \\
\hline & Evaluation 1 & Evaluation 2 & Evaluation 3 & Evaluation 1 & Evaluation 2 & Evaluation 3 \\
\hline Without pain & $0(0 \%)$ & $5(31 \%)$ & $7(44 \%)$ & $0(0 \%)$ & $6(37 \%)$ & $6(37 \%)$ \\
\hline Pain once a week & $0(0 \%)$ & $2(13 \%)$ & $3(19 \%)$ & $0(0 \%)$ & $0(0 \%)$ & $1(6 \%)$ \\
\hline Pain twice or more per week & $16(100 \%)$ & $9(56 \%)$ & $6(37 \%)$ & $16(100 \%)$ & $10(63 \%)$ & $9(56 \%)$ \\
\hline $\mathrm{p}^{*}$ & \multicolumn{3}{|c|}{0.001} & \multicolumn{3}{|c|}{0.008} \\
\hline
\end{tabular}

* Friedman test - intragroup evaluation. ANOVA - intergroup evaluation - p >0.05(N.S.). Group $1=$ ten physiotherapy sessions (ultrasound and kinesiotherapy); Group $2=$ three sessions of shockwave therapy. Evaluation $1-$ before treatment; Evaluation $2=$ immediately after treatment; Evaluation $3=$ three months after treatment

Table 2 - Number of hours of pain per day in Groups 1 and 2 before and after treatment

\begin{tabular}{|c|c|c|c|c|c|c|}
\hline \multirow{2}{*}{$\begin{array}{l}\text { Number of hours } \\
\text { of pain per day }\end{array}$} & \multicolumn{3}{|c|}{ Group $1(n=16)$} & \multicolumn{3}{|c|}{ Group $2(n=16)$} \\
\hline & Evaluation 1 & Evaluation 2 & Evaluation 3 & Evaluation 1 & Evaluation 2 & Evaluation 3 \\
\hline 0 hours & $0(0 \%)$ & $6(37 \%)$ & $8(50 \%)$ & $0(0 \%)$ & $6(37 \%)$ & $7(44 \%)$ \\
\hline Less than 4 hours & $7(44 \%)$ & $8(50 \%)$ & $7(44 \%)$ & $8(50 \%)$ & $9(56 \%)$ & $8(50 \%)$ \\
\hline At least four hours & $9(56 \%)$ & $2(13 \%)$ & $1(6 \%)$ & $8(50 \%)$ & $1(6 \%)$ & $1(6 \%)$ \\
\hline $\mathrm{p}^{*}$ & \multicolumn{3}{|c|}{0.000} & \multicolumn{3}{|c|}{0.001} \\
\hline
\end{tabular}

* Friedman test - intragroup evaluation. ANOVA - intergroup evaluation - $\mathrm{p}>0.05$ (N.S.). Group $1=$ ten physiotherapy sessions (ultrasound and kinesiotherapy); Group 2 = three sessions of shockwave therapy. Evaluation 1 - before treatment; Evaluation $2=$ immediately after treatment; Evaluation $3=$ three months after treatment

Table 3 - Patient distribution according to intensity of morning pain on visual analog scale (VAS) in Groups 1 and 2 before and after treatment

\begin{tabular}{|c|c|c|c|c|c|c|}
\hline \multirow[t]{2}{*}{ VAS } & \multicolumn{3}{|c|}{ Group $1(\mathrm{n}=16)$} & \multicolumn{3}{|c|}{ Group $2(n=16)$} \\
\hline & Evaluation 1 & Evaluation 2 & Evaluation 3 & Evaluation 1 & Evaluation 2 & Evaluation 3 \\
\hline Good (0-1) & $0(0 \%)$ & $7(44 \%)$ & $9(56 \%)$ & $1(6 \%)$ & $7(44 \%)$ & $10(62 \%)$ \\
\hline Regular (2-5) & $1(6 \%)$ & $5(31 \%)$ & $5(31 \%)$ & $3(19 \%)$ & $4(25 \%)$ & $4(25 \%)$ \\
\hline Poor (6-10) & $15(94 \%)$ & $4(25 \%)$ & $2(13 \%)$ & $12(75 \%)$ & $5(31 \%)$ & $2(13 \%)$ \\
\hline $\mathrm{p}^{*}$ & \multicolumn{3}{|c|}{0.000} & \multicolumn{3}{|c|}{0.000} \\
\hline
\end{tabular}

* Friedman test - intragroup evaluation. ANOVA - intergroup evaluation - $\mathrm{p}>0.05$ (N.S.). Group $1=$ ten physiotherapy sessions (ultrasound and kinesiotherapy); Group 2 = three sessions of shockwave therapy. Evaluation 1 - before treatment; Evaluation $2=$ immediately after treatment; Evaluation $3=$ three months after treatment

Table 4 - Patient distribution according to intensity of gait pain on visual analog scale (VAS) in Groups 1 and 2 before and after treatment

\begin{tabular}{|c|c|c|c|c|c|c|}
\hline \multirow[t]{2}{*}{ VAS } & \multicolumn{3}{|c|}{ Group $1(n=16)$} & \multicolumn{3}{|c|}{ Group $2(\mathrm{n}=16)$} \\
\hline & Evaluation 1 & Evaluation 2 & Evaluation 3 & Evaluation 1 & Evaluation 2 & Evaluation 3 \\
\hline Good (0-1) & $2(13 \%)$ & $10(62 \%)$ & $11(69 \%)$ & $2(13 \%)$ & $8(50 \%)$ & $10(62 \%)$ \\
\hline Regular (2-5) & $3(19 \%)$ & $3(19 \%)$ & $3(19 \%)$ & $2(13 \%)$ & $3(19 \%)$ & $3(19 \%)$ \\
\hline Poor (6-10) & $11(69 \%)$ & $3(19 \%)$ & $2(13 \%)$ & $12(75 \%)$ & $5(31 \%)$ & $3(19 \%)$ \\
\hline $\mathrm{p}^{*}$ & \multicolumn{3}{|c|}{0.002} & \multicolumn{3}{|c|}{0.001} \\
\hline
\end{tabular}

* Friedman test - intragroup evaluation. ANOVA - intergroup evaluation $-\mathrm{p}>0.05$ (N.S.). Group $1=$ ten physiotherapy sessions (ultrasound and kinesiotherapy); Group $2=$ three sessions of shockwave therapy. Evaluation 1 - before treatment; Evaluation $2=$ immediately after treatment; Evaluation $3=$ three months after treatment 
Table 5 - Patient distribution according to intensity of orthostatic pain on visual analog scale (VAS) in Groups 1 and 2 before and after treatment

\begin{tabular}{|c|c|c|c|c|c|c|}
\hline \multirow[t]{2}{*}{ VAS } & \multicolumn{3}{|c|}{ Group $1(n=16)$} & \multicolumn{3}{|c|}{ Group $2(n=16)$} \\
\hline & Evaluation 1 & Evaluation 2 & Evaluation 3 & Evaluation 1 & Evaluation 2 & Evaluation 3 \\
\hline Good (0-1) & $2(13 \%)$ & $6(37 \%)$ & $8(50 \%)$ & $1(6 \%)$ & $7(44 \%)$ & $8(50 \%)$ \\
\hline Regular (2-5) & $2(13 \%)$ & $6(37 \%)$ & $5(31 \%)$ & $2(13 \%)$ & $3(19 \%)$ & $5(31 \%)$ \\
\hline Poor (6-10) & $12(75 \%)$ & $4(25 \%)$ & $3(19 \%)$ & $13(81 \%)$ & $6(37 \%)$ & $3(19 \%)$ \\
\hline $\mathrm{p}^{*}$ & \multicolumn{3}{|c|}{0.003} & \multicolumn{3}{|c|}{0.000} \\
\hline
\end{tabular}

* Friedman test - intragroup evaluation. ANOVA - intergroup evaluation $-\mathrm{p}>0.05$ (N.S.). Group $1=$ ten physiotherapy sessions (ultrasound and kinesiotherapy); Group 2 = three sessions of shockwave therapy. Evaluation $1-$ before treatment; Evaluation $2=$ immediately after treatment; Evaluation $3=$ three months after treatment

Table 6 - Patient distribution according to intensity of pain in calcaneus obtained by Fischer's algometer in Group 1 (conventional physiotherapy) and Group 2 (shockwave physiotherapy) before the treatment, immediately afterwards, and three months later

\begin{tabular}{|c|c|c|c|c|c|c|}
\hline \multirow{2}{*}{$\begin{array}{l}\text { Fischer's algometer } \\
\text { (calcaneus) }\end{array}$} & \multicolumn{3}{|c|}{ Group 1 ( 24 feet treated) } & \multicolumn{3}{|c|}{ Group 2 (26 feet treated) } \\
\hline & Evaluation 1 & Evaluation 2 & Evaluation 3 & Evaluation 1 & Evaluation 2 & Evaluation 3 \\
\hline Up to $4 \mathrm{~kg}$ (very poor) & $5(21 \%)$ & $0(0 \%)$ & $0(0 \%)$ & $6(23 \%)$ & $1(4 \%)$ & $0(0 \%)$ \\
\hline$>4-6 \mathrm{~kg}$ (poor) & $8(33 \%)$ & $1(4 \%)$ & $0(0 \%)$ & $11(42 \%)$ & $0(0 \%)$ & $0(0 \%)$ \\
\hline$>6-8 \mathrm{~kg}$ (regular) & $9(38 \%)$ & $5(21 \%)$ & $2(8 \%)$ & $6(23 \%)$ & $4(15 \%)$ & $0(0 \%)$ \\
\hline > 8-10 kg (good) & $2(8 \%)$ & $8(33 \%)$ & $1(4 \%)$ & $3(12 \%)$ & $6(23 \%)$ & $5(19 \%)$ \\
\hline Without pain & $0(0 \%)$ & $10(42 \%)$ & $21(88 \%)$ & $0(0 \%)$ & $15(58 \%)$ & $21(81 \%)$ \\
\hline $\mathrm{p}^{*}$ & 0.000 & & & 0.000 & & \\
\hline
\end{tabular}

* Friedman test - intragroup evaluation. ANOVA - intergroup evaluation $-\mathrm{p}>0.05$ (N.S.). Group $1=$ ten physiotherapy sessions (ultrasound and kinesiotherapy); Group 2 = three sessions of shockwave therapy. Evaluation 1 - before treatment; Evaluation $2=$ immediately after treatment; Evaluation $3=$ three months after treatment

Table 7 - Patient distribution according to intensity of pain in gastrocnemius obtained by Fischer's algometer in Groups 1 and 2 before and after treatment

\begin{tabular}{|c|c|c|c|c|c|c|}
\hline \multirow{2}{*}{$\begin{array}{l}\text { Fischer's algometer } \\
\text { (gastrocnemius) }\end{array}$} & \multicolumn{3}{|c|}{ Group 1 (24 feet treated) } & \multicolumn{3}{|c|}{ Group 2 (26 feet treated) } \\
\hline & Evaluation 1 & Evaluation 2 & Evaluation 3 & Evaluation 1 & Evaluation 2 & Evaluation 3 \\
\hline Up to $4 \mathrm{~kg}$ (very poor) & $9(38 \%)$ & $2(8 \%)$ & $2(8 \%)$ & $13(50 \%)$ & $4(15 \%)$ & $4(15 \%)$ \\
\hline$>4-6 \mathrm{~kg}$ (poor) & $2(8 \%)$ & $4(17 \%)$ & $3(13 \%)$ & $4(15 \%)$ & $3(12 \%)$ & $6(23 \%)$ \\
\hline$>6-8 \mathrm{~kg}$ (regular) & $0(0 \%)$ & $1(4 \%)$ & $2(8 \%)$ & $0(0 \%)$ & $1(4 \%)$ & $3(12 \%)$ \\
\hline$>8-10 \mathrm{~kg}$ (good) & $0(0 \%)$ & $2(8 \%)$ & $2(8 \%)$ & $0(0 \%)$ & $1(4 \%)$ & $0(0 \%)$ \\
\hline Without pain & $13(54 \%)$ & $15(63 \%)$ & $15(63 \%)$ & $9(35 \%)$ & $17(65 \%)$ & $13(50 \%)$ \\
\hline $\mathrm{p}^{*}$ & \multicolumn{3}{|c|}{0.000} & \multicolumn{3}{|c|}{0.000} \\
\hline
\end{tabular}

* Friedman test - intragroup evaluation. ANOVA - intergroup evaluation $-\mathrm{p}>0.05$ (N.S.). Group $1=$ ten physiotherapy sessions (ultrasound and kinesiotherapy); Group 2 = three sessions of shockwave therapy. Evaluation $1-$ before treatment; Evaluation $2=$ immediately after treatment; Evaluation $3=$ three months after treatment

Table 8 - Frequency and percentage of patients who had stopped using analgesics three months after treatment

\begin{tabular}{lcccc}
\hline & \multicolumn{2}{c}{ Stopped using analgesics three months after treatment } & \multirow{2}{*}{$\begin{array}{c}\text { Total number who used analgesics } \\
\text { before treatment }\end{array}$} & $\mathrm{p}$ \\
\cline { 2 - 3 } & Yes & No & $13(100 \%)$ & 0.411 \\
\hline Group 1 & $10(76.9 \%)$ & $3(23.1 \%)$ & $13(100 \%)$ & \\
\hline
\end{tabular}

Fisher's exact test - $\mathrm{p}>0.5$ (N.S.) 
present study, there were no complications from the use of radial shockwaves.

The aim of the present study was to comparatively evaluate shockwaves with conventional physiotherapeutic treatment for plantar fasciitis. All patients were advised to perform active stretching of the gastrocnemius twice per day to improve ankle flexibility, but only group 1 (conventional physiotherapy) underwent a kinesiotherapy regimen under guidance from a physiotherapist at all treatment sessions. Reinforcement of instructions by a physiotherapist at the ten treatment sessions might have influenced the good results observed for this group. More specifically, the constancy of such guidance might have greatly contributed to adherence to the exercise program and to the change of habits. Although the quality of this treatment depends on the physiotherapist, it gives good results when applied carefully and judiciously. In group 2 (shockwave therapy), the patients were individually advised to perform active stretching of the gastrocnemius, but they did not receive any specific kinesiotherapy regimen during the treatment sessions and did not have any subsequent follow-up. All guidance was given during the three treatment sessions and at the assessments. Shockwave therapy might be more efficient for treatment of plantar fasciitis pain than conventional physiotherapy, but comprehensive rehabilitation programs that are implemented carefully and with good guidance increase patient adherence and promote both pain reduction and functional improvement.

Three months after treatment, the patients in both groups presented reduced morning pain, gait pain and orthostatic pain; decreased duration (hours/day) and periodicity (number of crises per week) of pain; and diminished use of analgesics.
There was no difference in the efficacy of the two treatments, but the more immediate effect of shockwave therapy provided faster relief from pain and incapacitation. For shockwave treatment to be effective and long-lasting, it must be complemented with the use of insoles for impact absorption, as well as changes in footwear, weight loss, restrictions on running or walking long distances and stretching of the gastrocnemius and plantar fascia. ${ }^{20,28}$ Active stretching of the gastrocnemius muscle and the plantar fascia may improve painful symptoms in cases of plantar fasciitis. . $^{10,15,20,27,28}$ In the present study, all treated patients were advised to perform such stretching. Better functioning of the foot and ankle, particularly with regard to gait, is of prime importance for maintaining the improvements gained by therapy.

Correct clinical and functional diagnosis of plantar fasciitis together with a simple but well implemented rehabilitation program is a good approach to treating this disorder. It is therefore not always necessary to utilize sophisticated resources or technology to achieve optimal results. ${ }^{10,15,27}$ The results of the present study show that a comprehensive rehabilitation program might be effective for treating plantar fasciitis, despite its simplicity. These results are not in agreement $t^{4,20,29}$ with the findings of Ogden, ${ }^{30-32}$ who reported that shockwaves were greatly superior for treating plantar fasciitis as compared to other treatments, and that symptoms disappeared in $90 \%$ of the cases treated.

\section{CONCLUSION}

The two evaluated treatments were effective for reducing pain and incapacitation among patients with plantar fasciitis for at least three months after treatment.

\section{REFERENCES}

1. Ogden JA, Alvarez RG, Levitt R, Marlow M. Shock wave therapy (Orthotripsy) in musculoskeletal disorders. Clin Orthop Relat Res. 2001;387:22-40.

2. Ogden JA, Tóth-Kischkat A, Schultheiss R. Principles of shock wave therapy. Clin Orthop Relat Res. 2001;387:8-17.

3. Ogden JA, Alvarez RG, Levitt RL, Johnson JE, Marlow ME. Electrohydraulic high-energy shock-wave treatment for chronic plantar fasciitis. J Bone Joint Surg Am. 2004;86:2216-28.

4. Haake M, Buch M, Schoellner C, Goebel F, Vogel M, Mueller I, et al. Extracorporeal shock wave therapy for plantar fasciitis: randomised controlled multicentre trial. BMJ. 2003;327:75-9.

5. Haupt G, Diesch R, Straub T, Penninger E, Frolich T, Scholl J, et al. Radial Shock Wave Therapy in Heel Spurs. Der Nieder Gelassene Chirurg. 2002;6:1-6.
6. Gerdesmeyer L, Weil L, Maier M, Lohrer H, Frey C, Feder K, et al. Treatment of Painful Heel. Swiss Dolor Clast: Summary of Clinics Study Results-FDA/PMA Approval. May 2007. Available from: http:// www.dolorclast.com/page_clinicalstudies.php

7. Gerdesmeyer L, Gollwitzer H, Diehl P, Wagner K. Radial extracorporeal shock wave therapy in orthopaedics. J Miner Stoffwechs. 2004;11:369 .

8. Straub T, Penninger E, Frolich T, Lohrer H, Scholl J, Diesch R, et al Successful therapy of painful fasciitis plantar by radial shock wave: a prospective, multi-centric and placebo-controlled study. Int J Sports Med. 1999;20:21-3

9. Lohrer H, Schoell J, Arentz S, Froelich T, Straub T, Penninger E, et al. Effectiveness of radial shock wave therapy (RSWT) on tennis elbow and plantar fasciitis. In: Annual Simposium of Canadian Academy of Sport Medicine; 2001 Jul 4-7, Alberta, Canada. 
10. Zanon RG, Kundrat A, Imamura M. Ultra-som contínuo no tratamento da fasciite plantar crônica. Acta Ortop Bras. 2006;14:137-40.

11. Roxas M. Plantar Fasciitis: diagnosis and therapeutic considerations. Alt Med Rev. 2005;10:83-93.

12. Helbig K, Herbert C, Schostok T, Brown M, Thiele R. Correlation between the duration of pain and the success of shock wave therapy. Clin Orthop Relat Res. 2001;387:68-71.

13. Huang YC, Wang LY, Wang HC, Chang KL, Leong CP. The relationship between the flexible flatfoot and plantar fasciitis: ultrasonographic evaluation. Chang Gung Med J. 2004;27:443-8.

14. Carvalho Junior AE, Imamura M, Moraes Filho DC. Talalgias. In: Hebert S, Xavier R, Pardini Junior AG, Barros Filho TEP. Ortopedia e traumatologia: princípios e prática. 3a ed. Porto Alegre: Artmed; 2003. p. 550-6.

15. Imamura M, Carvalho Junior AE, Fernandes TD, Leivas TP, Salomão O. Fasciite Plantar: Estudo Comparativo. Rev Bras Ortop. 1996;31:5616.

16. Riddle DL, Pulisic M, Sparrow K. Impact of demographic and impairment- related variables on disability associated with plantar fasciitis. Foot Ankle Int 2004;25:311-7.

17. Rompe JD. Repetitive low-energy shock wave treatment is effective for chronic symptomatic plantar fasciitis. Knee Surg Sports Traumatol Arthrosc. 2007; 15:107.

18. Greve, J, Alonso, A, Bordini AC, Camanh GL. Correlation between body mass index and postural balance. Clinics. 2007;62:717-20.

19. Hammer DS, Adam F, Kreutz A, Rupp S, Kohn D, Seil R. Ultrasonographic evaluation at 6-month follow-up of plantar fasciitis after ESWT. Arch Orthop Trauma Surg. 2005;125:6-9.

20. Buchbinder R, Ptasznik R, Gordon J, Buchanan J, Prabaharan V, Forbes A. Ultrasound-guided extracorporeal shockwave therapy for plantar fasciitis: a randomized controlled trial. JAMA 2002;288:1364-72.
21. Liang WH, Wang TG, Chen WS, Hou SM. Thinner Plantar Fascia Predicts Decreased Pain after Shock Wave Therapy. Clin Orthop Relat Res 2007;460:219-25.

22. Mulligan EP. Reabilitação da perna, do tornozelo e do pé. In: Andrews RA. et al. Reabilitação física das lesões desportivas. $2^{a}$ ed. Rio de Janeiro: Guanabara Koogan; 2000. p.224.

23. Weil LS Jr, Roukis TS, Weil LS, Borrelli AH. Extracorporeal shockwave treatment of chronic plantar fasciitis: indication, protocol intermediate results and comparison of results to fascitomy. J Foot Ankle Surg. 2002;41:166-72.

24. Chen HS, Chen LM, Huang TW. Treatment of painful heel syndrome with shock waves. Clin Orthop Relat Res. 2001;387:41-6.

25. Hammer DS, Rupp S, Kreutz A, Pape D, Kohn D, Seil R. Extracorporeal shockwave therapy in patients with chronic proximal plantar fasciitis. Foot Ankle Int. 2002; 23:309-13.

26. Wang CJ, Chen HS, Huang TW. Shockwave therapy: a one-year followup study. Foot Ankle Int. 2002;23:204-7.

27. DiGiovanni BF, Nawoczenski DA, Lintal ME, Moore EA, Murray JC, Wilding GE, et al. Tissue-specific plantar fascia-stretching exercise enhances outcomes in patients with chronics heel pain. J Bone Joint Surg Am. 2003;85:1270-77.

28. Gill LH, Kiebzak GM. Outcome of nonsurgical treatment for plantar fasciitis. Foot Ankle Int. 1996;17:527-32.

29. Speed CA, Nichols D, Wies J, Humphreys H, Richards C, Burnet S, et al. Extracorporeal shock wave therapy for plantar fasciitis. A double blind randomised controlled trial. J Orthop Res. 2003;21:937-40.

30. Ogden JA. Extracorporeal shock wave therapy for plantar fasciitis: randomised controlled multicentre trial. Br J Sports Med. 2004;38:382

31. Rompe JD. Shock-wave therapy for plantar fasciitis. J Bone Joint Surg Am. 2005; 87:680-83.

32. Ogden JA, Alvarez RG, Marlow M. Shockwave therapy in plantar fasciitis: A meta-analysis. Foot and Ankle Int. 2002;23:301-8. 